\title{
Avaliação do Funcionamento Cognitivo por Meio do CAT-A: Evidências de Validade
}

\author{
Cognitive Assessment Using the CAT-A: Validity Evidence
}

\author{
Maria de Fátima Xavier ${ }^{a}$ \&Anna Elisa de Villemor-Amaral ${ }^{*}, b$ \\ ${ }^{a}$ Faculdades Intergradas Einstein de Limeira, Limeira, Brasil \\ $\&{ }^{b}$ Universidade São Francisco, Itatiba, Brasil
}

\begin{abstract}
Resumo
O objetivo desse estudo foi trazer evidências de validade do CAT-A para avaliação do funcionamento cognitivo em crianças. Correlacionou-se indicadores cognitivos no CAT-A; DFH e Rorschach no Sistema Compreensivo. Inicialmente, com base no DFH, selecionou-se 46 crianças de 7 e de 12 anos, divididas em dois grupos, um com 32 participantes com nível cognitivo abaixo do esperado e outro com 14 com nível acima do esperado. Em seguida aplicou-se o Rorschach e o CAT-A, individualmente. Os índices de correlação significativa entre os instrumentos permitiram encontrar evidências de validade para o CAT-A na avaliação da cognição. Quanto aos indicadores que avaliam o nível de desenvolvimento da percepção no CAT-A, obteve-se diferenças de média entre os dois grupos, cognição elevada e cognição abaixo do esperado para idade, denotando convergência entre os resultados das três técnicas. Os resultados não apenas trouxeram um avanço para o uso do CAT-A como também abrem novas perspectivas de pesquisas com esse instrumento. Palavras-chave: Avaliação psicológica, validade de critério, percepção, Rorschach, DFH.
\end{abstract}

\begin{abstract}
The aim of this study was to verify the validity of the Children Apperception Test (CAT-A) for cognitive assessment of children. The results of CAT-A were correlated with Human Figure Drawing (HFD) and the Rorschach Method. Based on the data of HFD, the sample was composed of 46 children: 32 with low scores and 14 with a higher level of cognition. The Rorschach and the CAT-A were administered individually. The rates of significant correlation between the instruments pointed out for validity evidence for the CAT-A in the assessment of cognition. As for indicators that assess the development level of perception in the CAT-A, it was found some differences between the two groups, denoting convergence between the results of HFD and CAT-A. Thus, the significant correlation of the CAT-A and the two other instruments is an evidence of validity to CAT-A to assess cognitive aspects and allow some advances for its use and for further researches using this technique.

Keywords: Psychological assessment, criterion validity, perception, Rorschach, HFD.
\end{abstract}

Desde sua criação, o CAT-A é um instrumento bastante utilizado em avaliações psicológicas, principalmente na clínica com crianças. Tendo como fundamento a teoria psicanalítica, vem sendo geralmente analisado com base nesses pressupostos teóricos sem que, durante muito tempo, houvesse interesse específico na comprovação da validade das interpretações atribuídas ao material fornecido pela criança. Tal realidade se refletiu num investimento restrito em pesquisas de validação, além dos primeiros estudos realizados por L. Bellak e S. S. Bellak (1949/ 1991). No Brasil essa situação se repete, sendo poucas as investigações para averiguar a cientificidade da técnica conforme busca em referências bibliográficas e nas ba- ses de dados eletrônicas Scielo, Medline, Indexpsi Periódicos - BVS-Psi, e PsycINFO, a partir das palavras-chave "Children Apperception Test", "CAT-A", "técnicas projetivas" e "avaliação da cognição". Constatou-se uma carência de estudos com intuito de verificar a validade e precisão desta técnica, principalmente em relação ao construto cognição. Assim, destaca-se o trabalho de Tardivo e Herzberg (1989) que analisaram os protocolos de crianças de 5 a 8 anos de ambos os sexos e constataram variações importantes na percepção dos diversos componentes das figuras, quando compararam as duas faixas etárias, verificando que inclusões ou exclusões de personagens ou outros objetos constituíram as diferenças mais marcantes entre os grupos.

No Brasil encontram-se estudos de evidências de validade correlacionando o CAT-A com outras variáveis, a maioria deles procurando criar um referencial de análise das respostas e sistematizar a interpretação. Savastano 
(1977) estudou dois grupos de alunos com o objetivo de compreender a dinâmica emocional dos mesmos. Castro (1990) verificou a hipótese de que a inibição nas atividades escolares poderia derivar de um distúrbio no processo de individuação do ego. Cunha, Nunes e Werlang (1991) analisaram os relatos de crianças pré-escolares, considerando a capacidade infantil de organizar ações num esquema temporal. Paiva (1992) analisou aspectos afetivos e cognitivos e o quanto estes convergiam com o desempenho escolar e, para isto, utilizou Procedimento de Desenhos-Estórias, o CAT-A e o Pré-Bender. Tardivo (1992) buscou elaborar categorias de interpretação normatizadas e verificar evidência de validade das mesmas, comparando-as com os resultados de outros testes projetivos. Felipe (1997) verificou a contribuição do CAT-A e do Procedimento de Desenho de Família com Estórias (DF-E) no diagnóstico das necessidades, conflitos e sentimentos de crianças de pais separados e em disputa judicial. Amaral, Magarian, Sousa e Aribi (2003) utilizaram as pranchas 3 e 4 do CAT-A, objetivando avaliar as características da figura materna e paterna, internalizadas. Antony e Ribeiro (2004) analisaram o funcionamento psicológico de crianças hiperativas, com diagnóstico de Transtorno de Déficit de Atenção/Hiperatividade, concluindo que as histórias narradas no instrumento indicaram sentimentos de inadequação, rejeição e incompreensão. Fonseca (2005) elaborou um referencial de análise para o CAT e o DFH (Desenho da Figura Humana) que pudesse discriminar um grupo de crianças com histórico de abuso sexual do grupo sem esse histórico e constatou evidências de validade para o objetivo proposto. Benczik (2005) destacou e adaptou categorias de indicadores do CAT-A com o propósito de discriminar o grupo de crianças com diagnóstico de TDAH do grupo de crianças sem TDAH, a partir da avaliação sugerida por Tardivo (1992). Seus resultados indicaram evidência de validade para discriminar crianças com TDAH e precisão entre avaliadores. A pesquisa de Silva e Villemor-Amaral (2006) elaborou categorias de indicadores de autoestima, com critérios bem definidos, a serem verificadas no CAT-A. Os resultados apontaram evidência de validade e precisão entre avaliadores. O estudo de Villemor-Amaral e Xavier (2007) destacou indicadores relativos à relação materna, a partir do referencial de análise de Tardivo (1992) e evidenciou concordância satisfatória entre avaliadores para a maioria dos indicadores.

É importante enfatizar que a validade está primordialmente atrelada à precisão, condição primeira para garantir a confiabilidade das interpretações. Em outras palavras, antes de tudo, uma técnica de avaliação psicológica precisa ter um sistema objetivo e preciso de análise de respostas, para depois verificar se as interpretações originadas nesse sistema de análise são válidas. Entretanto, também são escassos os estudos que procuraram sistematizar modos de análise das respostas suficientemente objetivos que pudessem ser usados por clínicos diferentes com elevado grau de concordância entre si, o que atestaria a precisão do teste. Os criadores dessa técnica, Bellak e Bellak (1949/1991) propuseram formas de sistematização, sem entretanto estabelecer critérios suficientemente claros e objetivos para a classificação das respostas, o que pode levar a muitas divergências entre profissionais trabalhando sobre o material de um mesmo indivíduo. Assim, algumas pesquisas procuraram sistematizar e classificar respostas, dentre elas destaca-se a de Boulanger-Belleyguier (1957), Chauhan e Dhar (1981), Colsen (2001), Grassano (1996), Harris (1963), Haworth (1966), Hirsch (1984, 1987), Hojnoski, Morrison, Brown e Matthews (2006), Lis, Mazzeschi, Salcuni e Zennaro (2005), Quartier (2003), Scheffler (1975), Sharan, Mehta e Chaudhry (1995) e Radoszewska (2006). No Brasil estudos com esse intuito são ainda mais escassos, destacando-se o de Benczik, (2005), Castro (1990), Montagna (1987), Savastano (1977), Silva e Villemor-Amaral (2006), Tardivo (1992), Villemor-Amaral e Xavier (2007). A carência de diretrizes precisas para análise e interpretação das histórias relatadas dificulta o bom uso do método e é visando contribuir nesse sentido que esse estudo foi proposto.

Com esse fim, considerou-se relevante identificar nos relatos infantis a interferência de fatores cognitivos na produção das histórias, seja porque quase não se encontrou estudos específicos sobre esses aspectos nesse teste temático, seja em razão da importância de se discriminar distorções nos relatos decorrentes de problemas no desenvolvimento cognitivo daqueles de ordem predominantemente emocional.

Optou-se por realizar um estudo de validade de critério, comparando-se grupos contrastantes quanto ao rendimento intelectual em outra prova. Para isso foi necessário antes adaptar um sistema de análise das respostas com foco no funcionamento cognitivo, desenvolvido por Teglasi (2001) para o Teste de Apercepção Temática (TAT). Esse estudo, realizado previamente, foi detalhadamente apresentado por Xavier e Villemor-Amaral (2010), tendo-se demonstrado a precisão do sistema por meio do estudo de concordância entre examinadores (valores de kappa entre 0,52 e 0,97 ). Passou-se então à segunda etapa da pesquisa, que era a verificação da validade desse sistema para avaliação de aspectos cognitivos em crianças no CAT-A.

Além da comparação dos resultados de grupos contrastantes, optou-se também por comparar o desempenho no CAT-A com o desempenho no Rorschach, focando-se os indicadores para avaliação dos aspectos cognitivos. Como a cognição pode ser avaliada como resultante de várias funções, destacou-se a integração da percepção como função que evolui com o desenvolvimento e interfere decisivamente na capacidade de compreensão e solução de problemas.

Considerando esse aspecto, o Método de Rorschach permite aferir o processo de percepção, chamando a atenção para o fato de que as respostas revelam níveis diferentes de complexidade e organização do estímulo ambíguo - 
mancha de tinta. Foi com o Sistema Compreensivo (Exner, 1999), que o estudo desses aspectos ficou mais detalhado, e por meio da Tríade Cognitiva, obtêm-se diversos fatores cognitivos envolvidos na elaboração de cada resposta.

Weiner (1999) esclarece que, no Método de Rorschach, ao responder com que as manchas se parecem, o indivíduo precisa estruturar "cognitivamente o campo recorrendo à atenção, percepção, à memória, à tomada de decisão e à análise lógica, por um lado, e formação da imagem, por outro, mediante processos de associação, atribuição de significado e simbolização" (Weiner, 1999, p. 22). É possível considerar que os mesmos processos estejam implicados quando uma pessoa conta uma história a partir de um quadro. A natureza do estímulo e o tipo de tarefa diferem quanto ao grau de organização. No Rorschach o estímulo é menos estruturado e a tarefa não demanda uma narrativa, porém os mecanismos básicos do funcionamento cognitivo são necessariamente os mesmos.

Teglasi (2001) avança na compreensão dos processos cognitivos quando afirma que as narrativas aperceptivas temáticas permitem a avaliação da complexidade de esquemas cognitivos envolvidos na interpretação significativa baseada numa percepção exata da cena retratada no estímulo. Assim, as histórias do TAT revelam a capacidade perceptiva e o pensamento do indivíduo. Quando o sujeito interpreta a cena, fornece informação sobre a percepção - detalhes destacados - e também conceitual, o significado da cena. Portanto, uma percepção exata e integrada do estímulo incluiria uma relação entre o conceito e os elementos percebidos, como, por exemplo, uma faca na cozinha é uma ferramenta, mas numa sala de aula é uma arma. Assim, um nível elevado da integração perceptual leva a organização das sugestões emocionais e interpessoais contidas nas figuras, tais como expressões faciais, postura, e das características do estímulo que definem um contexto como objetos, fundo, vestuário e assim por diante. Dessa forma os modos de apreensão definem o conjunto perceptivo que impregna o conteúdo da resposta. Com base nas teorias de Piaget sobre o desenvolvimento cognitivo, é possível compreender que as estruturas conceituais como jogos, expectativas, ou esquemas organizam a entrada perceptual significativa da informação. A permanência do objeto e as várias conservações são exemplos comuns de tais estruturas (Piaget, 1978). Para Piaget a centralização, que significa colocar o foco em um aspecto do objeto, é um processo perceptual que conduz a distorção do objeto ao formular impressões parciais, à parte do contexto.

De acordo com Piaget (1978), a idade de 7/8 anos marca o começo da reversibilidade das operações mentais que é a possibilidade de pensar a ação e sua anulação por meio da representação do objeto. Nessa mesma faixa etária, Dworetzki (1939) observou no Rorschach o fim das condensações e o início de percepções mais adequadas, indicando que, a partir dessa idade, a criança é capaz de abandonar o ponto de vista subjetivo e pode ver os objetos tais como são. Assim, existe uma interdependência entre a percepção e o egocentrismo do pensamento. $\mathrm{O}$ egocentrismo estreita o campo de percepção, pois apreende como absoluta a percepção imediata individual. A criança deve então, no curso de seu desenvolvimento, capacitar-se a apreender o objeto sob vários aspectos, passando por várias etapas que representam adaptações mais e mais complexas, desde uma percepção global superficial, passando por uma análise que implica percepção de vários dados ao mesmo tempo, o que impede a visão do todo, até chegar à possibilidade de realizar estruturas variáveis como enumeração, descrição e interpretação.

Considerando as etapas de desenvolvimento cognitivo de Piaget (1978), espera-se que as respostas ao CAT-A sejam influenciadas pelo nível operatório da criança. Assim, no período pré-operatório, haveria predominância de histórias fantasiosas, isto é, com interferência maior de elementos pessoais na apreensão da cena retratada, levando a uma interpretação e percepção mais distorcida da mesma. Além disso, pode ocorrer a justaposição de ideias e o sincretismo de pensamento que é uma junção de partes sem que esteja explicitada a ligação entre elas. O pensamento capta a informação, mas não assimila totalmente, apenas a justapõe a outra ideia, preponderante. Assim, a criança indica dificuldade em construir história a partir do estímulo apresentado, pois ao fazê-lo, adiciona elementos externos, guiando-se mais por pensamentos e sentimentos individuais, levando a uma apreensão fantasiosa. Já no estágio das operações concretas, o relato da criança se atém ao estímulo, elaborando respostas precisas, convergentes com a cena retratada, uma vez que o pensamento se aplica predominantemente às informações reais e concretas disponíveis. Finalmente no período das operações formais, espera-se que o indivíduo elabore histórias interpretativas, ultrapassando as informações concretas contidas no estímulo, revelando a capacidade para abstração, perceber e lidar com intenções, estabelecer relações lógicas entre os personagens, entre as causas das ações destes e suas consequências, entre os meios e os fins.

Essa última etapa está bem descrita por Exner e Sendín (1999), que, em sua definição afirmam que a cognição é a capacidade do indivíduo de fazer relações entre as várias informações disponíveis, facilitando a compreensão de acontecimentos complexos, proporcionando adaptação. Assim, as emoções têm efeitos no processamento das informações, no como e no que pensamos, ou seja, efeitos na cognição como um todo (Sendín, 1999).

Tendo-se contextualizado a percepção como uma dimensão cognitiva que evolui conforme o desenvolvimento e varia de acordo com a capacidade intelectual, supõe-se que o desempenho das crianças no Rorschach e no CATA se diferenciará segundo o nível intelectual e série. Portanto, o objetivo desta pesquisa foi verificar a evidência de validade de critério por grupos contrastantes, e comparar os resultados com o Rorschach. O estudo de caráter 
quantitativo e qualitativo foi conduzido para averiguar se os indicadores de níveis de percepção adaptada para o CAT-A discriminam crianças da $1^{\mathrm{a}}$ e $4^{\mathrm{a}}$ série do ensino fundamental e se correlacionam com os indicadores cognitivos do Rorschach.

\section{Método}

\section{Participantes}

Participaram do estudo 139 crianças. Desse total, 77 eram do sexo feminino e 62 masculino. As idades variaram de 7 a 12 anos. Todos os sujeitos estavam matriculados numa escola da rede pública de uma cidade do interior do estado de São Paulo, frequentando a $1^{\mathrm{a}}$. série $(N=49)$ e a $4^{\mathrm{a}}$. série $(N=90)$ do ensino fundamental. As crianças foram distribuídas em dois grupos, considerando a pontuação no DFH. Um grupo com crianças com resultado elevado no DFH, composto por 14 sujeitos, sendo 5 da $1^{\text {a }}$. série e 9 da $4^{\text {a }}$. série, e um grupo com nível cognitivo abaixo do esperado para idade, formado por 32 crianças ( 16 da $1^{\text {a }}$. série e 16 da $4^{\text {a }}$. série). Quanto ao sexo $25(54,3 \%)$ feminino e $21(45,7 \%)$ masculino. As idades dos participantes variaram entre 7 e 12 anos $(M=8,9130$ e $D P=1,41148)$, sendo que $23,9 \%(N=11)$ com 7 anos, $21,7 \%(N=10)$ com 8 anos, $50 \%(N=23)$ de 10 e com 11 e 12 anos $2,2 \%(N=1)$ respectivamente. Desse total, 21 $(45,7 \%)$ frequentando a $1^{\text {a }}$. série e $25(54,3 \%)$ a $4^{\text {a }}$ série do ensino fundamental.

\section{Instrumentos}

O Teste do Desenho da Figura Humana (DFH - Escala Sisto) - propõe avaliar aspectos cognitivos em crianças. Na presente pesquisa, optou-se por utilizar o sistema de Sisto que consta de 30 itens selecionados a partir dos 51 itens do teste original de Florence Goodenough destacados em 1926. Os 30 itens que devem ser verificados no teste são presença de: 1 . boca; 2 . nariz; 3. braço-perna; 4 . roupa; 5. pescoço; 6 . tronco; 7. coordenação motora; 8 . duas ou três peças de vestir; 9. pernas; 10. pés; 11. pescoço integrado; 12. pernas e braços na posição; 13. pupila; 14. ombros; 15. cabelos; 16. braços; 17. dedos; 18. olhos; 19. braço, cotovelo-ombro; 20. contorno de braços e pernas; 21. contorno de tronco; 22. traços fisionômicos; 23. desenho sem transparência; 24 . vestimenta coerente; 25. contorno da cabeça; 26 . boca e nariz; 27 . quatro peças de vestir; 28. polegar; 29. queixo e 30 . orelhas. Diversos estudos de precisão e evidências de validade foram realizados, conforme citado no manual (Sisto, 2005), com resultados satisfatórios, atestando a validade e precisão desse sistema para avaliar desenvolvimento cognitivo.

O Teste de Apercepção Infantil com Figuras de Animais - Children's Apperception Test - CAT-A - é composto por uma série de 10 pranchas com figuras de animais em várias situações humanas. Destina-se a crianças de 3 a 10 anos de ambos os sexos e é analisado a partir de dez variáveis que devem ser observadas em cada história. Para esta pesquisa, adaptou-se e operacionalizou-se as categorias de indicadores de integração perceptual e níveis de percepção do sistema de avaliação da cognição elaborado por Teglasi (2001) para o TAT. Esse sistema foi utilizado por considerar que o mesmo acrescenta e converge com a análise do CAT-A proposta por L. Bellak e S. S. Bellak (1949/1991). Tal sistematização investiga os níveis de integração perceptual, quais sejam; divergente, literal, impreciso e acurado. Uma descrição detalhada desse modo de classificação das respostas encontra-se na publicação de Xavier e Villemor-Amaral (2010).

O Método de Rorschach é composto por dez lâminas com manchas de tinta das quais cinco são acromáticas e cinco cromáticas (duas em vermelho e preto e três policromáticas), que são, em geral, escassamente estruturadas. Para avaliação cognitiva pautou-se nas variáveis que compõem a tríade cognitiva destacadas no Sistema Compreensivo.

Encontrou-se diversos autores que utilizaram o método Rorschach em crianças com o intuito de investigar o desenvolvimento cognitivo. Dentre esses destaca-se a pesquisa de Dworetzki (1939) que utilizou o método Rorschach para analisar o desenvolvimento da percepção em crianças, demonstrando a evolução das respostas de acordo com a faixa etária e o estudo de Beizmann (1970) que procurou discriminar aspectos do funcionamento mental de crianças no Rorschach. No Brasil, encontram-se estudos que demonstram a validade do Rorschach para avaliar aspectos emocionais e cognitivos em crianças (Adrados, 1985; Güntert, Yazigi, \& Behalau, 2000; Jacquemin, 1975).

\section{Procedimento}

Após autorização da instituição de ensino para aplicação dos instrumentos, o projeto de pesquisa foi submetido e aprovado pelo Comitê de Ética da Universidade São Francisco. Os pais das crianças assinaram Termo de Consentimento Livre e Esclarecido e aplicou-se o DFH (Sisto, 2005) coletivamente em uma sessão, conforme as instruções dadas por esse autor. Os desenhos da figura humana foram avaliados por um psicólogo experiente e com domínio dessa técnica. Considerou-se presença ou ausência dos itens em cada critério, atribuindo-se 1 para presença e 0 para ausência, sendo que a pontuação geral do sujeito foi o produto da soma total das pontuações de cada item.

O Método de Rorschach (SC) foi aplicado individualmente, seguindo as instruções contidas no manual de Exner (1999). Os protocolos do Rorschach foram codificados conforme os critérios do Sistema Compreensivo e $33 \%$ foram avaliados por dois juízes independentes, cegos quanto aos resultados dos outros instrumentos, com o propósito de assegurar fidedignidade dos resultados.

Para esse estudo consideraram-se variáveis da Tríade Cognitiva relacionadas com o processamento da informação, mediação e ideação, quais sejam, Lambda (L) que indica em que medida as respostas foram determinadas somente pela forma da mancha; $W: D: D d$, proporção que indica o modo de apreensão da realidade - se mais sinté- 
tica, analítica ou detalhista; $Z f$ indicador da capacidade de integração da percepção e elaboração do pensamento; $P S V$ que sugere perseverações e estereotipias, $D Q+, D Q v$ que revelam a capacidade de estabelecer relações entre os estímulos observados ou uma percepção vaga e imprecisa; $W D A \%$ indicador de acuidade perceptiva e adequação à realidade; $M$ que está relacionado à inteligência e criatividade e finalmente os Códigos Especiais Críticos (Sum6 e Wsum6) que revelam deslizes cognitivos que podem sugerir patologias de percepção e pensamento.

A aplicação do CAT-A foi individual, feita em outro dia, após o Rorschach conforme a recomendação de Hirsch (1987). Para as análises dos protocolos utilizouse uma ficha de avaliação que contém os indicadores de integração e nível perceptual para avaliar cognição (Xavier \& Villemor-Amaral, 2010), quais sejam: Grau de Congruência com o Estímulo - em que medida na história a criança desconsidera ou interpreta mal as emoções, ou má percepção; desconsidera ou se equivoca com as idades dos personagens; atribui importância exagerada a detalhes irrelevantes do estímulo; a ênfase é mais perceptual do que conceitual; vacila ou mostra-se indecisa sobre o significado do estímulo; ignora algum elemento que seria importante para a história, embora a percepção seja adequada; apreende os relacionamentos e os afetos que são pertinentes ao estímulo, mas não capta a sutileza dos afetos, sua intensidade, ou a sequência dos acontecimentos; a narrativa reflete um conjunto de acontecimentos realísticos e uma compreensão apropriada de causalidade social. Quanto aos Níveis de Integração Perceptual considera-se quatro: Nivel um: Divergente a criança confunde as emoções e os relacionamentos ou interpreta mal. Falha em reconhecer as tensões no estímulo; Nivel dois: Literal - há uma dificuldade de captar o significado implícito, consegue identificar as idades e emoções dos personagens, mas falha em identificar o processo psicológico que conecta cada evento, cada emoção, cada ação; Nivel três: Impreciso - o narrador reconhece o estado de tensão e a história captura, de modo geral, as implicações do estímulo em relação às emoções e relacionamentos retratados, entretanto o ajuste não é preciso; Nivel quatro: Acurado - O narrador inclui todas as pistas e sutilezas na interpretação das emoções e relacionamentos. Existe uma interpretação significativa da configuração do estímulo que captura de modo acurado e específico o clima da cena (Xavier \& Villemor-Amaral, 2010). Tais categorias foram pontuados por presença (P) ou ausência (A), em cada prancha, nos critérios para análise da integração perceptual. A pontuação geral do sujeito foi produto da soma total das pontuações da integração perceptual e partir disto foi verificado a predominância do nível, que foi considerado presente toda vez que em mais da metade das histórias ele foi pontuado. Para assegurar maior confiabilidade nos resultados e também para verificar a precisão nas análises do CAT-A, 26,08\% dos protocolos dos sujeitos, foram submetidos à análise de dois juízes independentes e cegos quanto aos resultados dos outros instrumentos.

\section{Resultados e Discussão}

Para as análises dos resultados entre os grupos formados com base no desempenho no DFH - escala Sisto (2005), atribuiu-se zero ao grupo com nível cognitivo abaixo do esperado para idade e um ao grupo com rendimento acima do esperado para a idade. Esse procedimento foi adotado a fim de viabilizar a análise com o CAT-A. A partir dessa separação analisou-se a diferença de média entre os grupos, utilizando o $t$ de Student, para verificar se os mesmos se diferenciavam nas respostas dadas ao CAT-A. Além disso, verificou-se quais os indicadores do CAT-A selecionados para avaliar o nível de percepção se correlacionavam de forma positiva e significativa com as variáveis da tríade cognitiva do Rorschach (SC).

\section{Análise das Correlações entre CAT e DFH}

No que se refere a diferença de média das respostas ao CAT-A dadas pelo grupo de cognição alta e baixa separados pelo DFH, aplicou-se o teste $t$ Student. Os dados podem ser conferidos na Tabela 1.

Tabela 1

Diferenças de Média entre os Dois Grupos nos Indicadores de Niveis de Percepção Verificados no CAT-A por Meio do t de Student

\begin{tabular}{lcccccc}
\hline Variáveis & Grupo & $N$ & $M$ & $t$ & $g l$ & $p$ \\
\hline Nível 2 Literal & 0 & 32 & 0,5938 & 3,677 & 44 & 0,001 \\
& & 1 & 14 & 0,0714 & & \\
Nível 4 Acurado & 0 & 32 & 0,0938 & $-3,988$ & 44 & 0,000 \\
& & 1 & 14 & 0,5714 & & \\
\hline
\end{tabular}

Os resultados indicaram que as crianças do grupo de cognição abaixo do esperado para a idade, segundo DFH, elaboraram histórias com nível de percepção literal, indicando diferença de média em relação ao grupo 1 . Isto indica, segundo Teglasi (2001), que as crianças constroem narrativas ancoradas no momento e na descrição da cena, mas não conseguem identificar o processo psicológico que conecta cada evento, cada emoção e cada ação. 
É possível falar sobre pontos da figura retratada no estímulo como cenas sobrepostas, separadas, sem relacionar bem uma com a outra. Geralmente elaboram histórias que retratam as emoções e ações dos personagens de forma simplista, vaga e estereotipada. Para ilustrar destaca-se a história da Prancha 6 elaborada por uma criança da $1^{\mathrm{a}}$. série de 7 anos e 6 meses.

Tem três ursos grandão e um pequenininho e um monte de pedras e os matos. Só. (O que estão fazendo?). Eles tão dormindo e o pequenininho ta olhando pra fora. Só. (Por que o pequeninho está olhando pra fora?). Que tem um monte de mato e ele não queria dormir. (Por quê?). Não sei. (O que aconteceu depois?). Nada.

$\mathrm{O}$ narrador consegue identificar os personagens, idades e a tensão retratada, mas a narrativa não deixa claro o passado, presente e futuro. Descreve o momento, retrata as emoções e ações de forma simplista.

No que se refere às crianças do grupo de cognição elevada, estas fizeram narrativas num nível de percepção acurada, sugerindo uma interpretação adequada e significativa da cena retratada no estímulo e ainda conseguiram capturar de forma precisa e específica o clima da cena. Indicaram nas histórias todas as pistas e sutilezas ao interpretarem as emoções e relacionamentos. Além disso, desenvolveram narrativas seguindo uma ordem cronológica dos fatos, considerando passado, presente e futuro. Pode-se observar sequência lógica e precisão nas palavras utilizadas, o que não impediu histórias criativas sem se afastarem do clima da cena (Teglasi, 2001). Isso pode ser verificado no relato da Prancha 1 de um sujeito da $1^{\text {a }}$. série com 7 anos e 3 meses de idade.

Era uma vez três pintinhos que eram muito travessos. A mamãe galinha foi buscar comida. Trouxe-a e foi fazer as compras e disse: - Esperem eu voltar, não se sirvam sozinhos. Então como eram muito travessos, comeram tudo sozinhos. O mais travesso era o do meio. (O que aconteceu?) Ouviram na porta que a mãe estava chegando e foram para o quarto deles. A mãe veio e viu que não tinha mais comida. Foi até o quarto e bateu neles. Assim aprenderam que não deviam desobedecer a mãe e servir sozinhos.

Aqui o narrador incluiu todas as pistas, emoções e relacionamentos (os personagens interatuam em função da comida). Contém os três tempos (passado, presente e futuro). Observa-se que há uma sequência lógica, precisão nas palavras utilizadas e elaborou uma história criativa sem se afastar muito do clima da cena retratada.

Considerando o nível de operação intelectual a partir das fases de desenvolvimento cognitivo estabelecidas por Piaget (1978) pode-se aventar que as crianças que elaboraram histórias condizentes com o nível de percepção literal estejam numa fase de transição entre o pré-operatório e operações concretas. Isto pode ser constatado no tipo de narrativa na qual se observa apego excessivo aos detalhes e informações concretas da prancha, mas também apontam esses detalhes separadamente sem fazer uma relação adequada entre os mesmos. Já as crianças consideradas pelo DFH de nível intelectual elevado, portanto acima do esperado para a sua idade, apresentaram narrativas com características interpretativas dos estímulos, ultrapassando as informações concretas contidas nos mesmos, conferindo-lhes novos significados, sem se afastarem do clima da cena. Essas características denotam interpretação e abstração da cena retratada coincidindo com o estágio das operações formais, portanto superior ao esperado para a idade destas crianças.

Após a análise de diferenças de médias entre os dois grupos separados pelo DFH, verificou se esta diferença ocorreria, também por série.

\section{Análise das Correlações entre CAT-A e Séries Escolares}

Tabela 2

Diferenças de Média, por Meio do t de Student, Entre a $1^{a}$. e $4^{a}$. Séries nos Indicadores Destacados para Verificar o Nível de Percepção no CAT-A

\begin{tabular}{lcccccc}
\hline Variáveis & Séries & $N$ & $M$ & $T$ & $g l$ & $p$ \\
\hline Nível 1 Divergente & 1 & 21 & 0,3333 & 2,771 & 44 & 0,008 \\
\multirow{2}{*}{ Nível 4 Acurado } & 4 & 25 & 0,0400 & & & \\
& 1 & 21 & 0,0000 & $-3,973$ & 44 & 0,000
\end{tabular}

Os resultados apontaram que as crianças de primeira série construíram histórias que coincidiram com o nível divergente $(p=0,008)$, denotando uma interpretação inadequada ou confundindo os relacionamentos e emoções, falhando no reconhecimento das tensões retratadas no estímulo. Isto pode decorrer da falta de parâmetros inter- nos para dimensionar as pistas da prancha, levando a uma interpretação inadequada das expressões faciais e das idades, assim como, o tipo de problema especificado não combina com a configuração do estímulo. Além disso, geralmente omitem o personagem principal, enfatizam detalhes irrelevantes sem perceber o conjunto. Para 
exemplificar traz-se o relato da Prancha 6 de uma criança da $1^{\text {a }}$. série de 8 anos e 3 meses.

Um dia mamãe urso morreu. $\mathrm{O}$ urso ficou sozinho. $\mathrm{O}$ pai morreu e o filhotinho com a mãe ficou. Aí veio um monte de urso. Aí apareceu dois ursos grandão. Aí depois morreu os três e aí acabou a história. (Por que eles morreram?). Por causa que eles tava doente.

Observa-se que houve falha no reconhecimento da tensão retratada na prancha (enquanto os ursos dormem, o ursinho está acordado). Assim, o tipo de problema retratado destoa com a configuração do estímulo e indica falta de lógica dos fatos.

As crianças da $4^{\mathrm{a}}$. série elaboraram histórias que correspondem ao nível de percepção acurado $(p<0,001)$ convergindo com o nível intelectual elevado, segundo o DFH. Esse tipo de narrativa inclui todas as pistas e sutilezas na interpretação das emoções e relacionamentos, mesmo ocorrendo algumas omissões ou confusões de detalhes pequenos, os sentimentos e os relacionamentos são entendidos na sua sutileza. Conseguem atribuir uma interpretação significativa à configuração do estímulo capturando de modo acurado e específico o clima da cena (Teglasi, 2001).

Analisando os resultados a partir das etapas de desenvolvimento cognitivo (Piaget, 1978), observa-se que as crianças da $1^{\mathrm{a}}$. série que construíram histórias que correspondem ao nível de percepção divergente, indicaram um funcionamento intelectual do período pré-operatório, apesar de estarem, considerando a idade $7 / 8$ anos, no estágio das operações concretas. $\mathrm{O}$ fato de construírem história com características de pensamento da fase anterior pode estar relacionado a não superação total do estágio anterior, mantendo características de pensamento do mesmo, talvez devido à transição de uma fase para outra ter ocorrido recentemente ou ainda estar ocorrendo. Sendo assim, no estágio pré-operacional é esperado que haja predominância de histórias fantasiosas, isto é, com interferência maior de elementos pessoais na apreensão da cena retratada, levando a uma interpretação e percepção distorcida da mesma. Além disso, pode ocorrer a justaposição de ideias e o sincretismo de pensamento que revela uma junção de partes sem que esteja explicitada a ligação entre elas. O pensamento capta a informação, mas não assimila totalmente, apenas a justapõe a outra ideia (preponderante). Assim, a criança indica dificuldade em construir história a partir do estímulo apresentado, pois ao fazê-lo, adiciona elementos externos, guiando-se mais por pensamentos e sentimentos individuais, levando a uma apreensão fantasiosa. As crianças de $4^{\mathrm{a}}$. série, segundo Piaget (1978), encontram-se no estágio das operações concretas. Assim, é possível, de um lado, verificar características dessa fase nas respostas ao CAT-A, pois construíram narrativas acuradas e convergentes à cena retratada, mas, de outro, estabeleceram novas relações entre os elementos, interpretando a cena conferindo relações entre as múltiplas informações denotando características de pensamento operatório formal.

\section{Correlação entre os Resultados do CAT e Rorschach}

Para atender o objetivo deste estudo, relacionou-se os indicadores do CAT-A selecionados para esta pesquisa com as variáveis do Rorschach. Os resultados significativos estão na Tabela 3.

Tabela 3

Coeficiente de Correlação de Pearson entre as Variáveis $W, D, D d<S, D Q+, D Q v$ e os Indicadores de Níveis de Percepção no $C A T-A$

\begin{tabular}{llllll}
\hline & & $\mathrm{S}$ & FQo & A & Hd \\
\hline Nível 4 acurado & $r$ & 0,48 & 0,30 & 0,37 & - \\
\multirow{2}{*}{ Nível 2 literal } & $p$ & 0,001 & 0,046 & 0,012 & - \\
& $r$ & - & - & - & 0,33 \\
& $p$ & - & - & - & 0,027
\end{tabular}

(**) Correlação significativa no nível $p<0,01$.

Os dados indicaram concordância positiva e moderada $(r=0,48)$ entre a variável $\mathrm{S}$ e o nível acurado no CAT, indicando que o grupo de cognição elevada deu mais respostas ao Rorschach usando o espaço em branco. Diante disso, é possível inferir que essas crianças, por meio da integração ou reversão figura fundo denotam a busca pela independência, auto-afirmação e indicam tendência à assertividade, o que corresponde a maior flexibilidade de pensamento (Exner \& Sendín, 1999). Assim, formulam respostas ao Rorschach e ao CAT-A, nas quais é possível observar uma exploração mais livre e rica dos estímulos, além de relatos precisos, coerentes, incluindo todas as pistas e sutilezas na interpretação das emoções e relacionamentos.

Constatou-se, ainda, que houve correlação positiva e baixa $(r=0,30)$ entre o indicador nível acurado do CATA e a variável FQo do Rorschach. Esse resultado coincide com o estudo de normatização do método Rorschach, no qual observou-se que a maioria das respostas é codificada como o, pois a frequência das respostas + é bastante baixa em todos os grupos. As respostas FQo envolvem contornos da mancha que existem e são geralmente consistentes com a forma do objeto que o indivíduo identifica e descreve (Exner, 1999). Segundo Exner e Sendín 
(1999) essa variável indica o grau de adequação do indivíduo que está relacionado a adequação perceptiva. Tal dado é convergente com o nível de percepção acurado, pois segundo Teglasi (2001) a narrativa apresenta uma sequência lógica e precisão nas palavras utilizadas. A história é criativa, mas retrata o clima da cena. Já entre o indicador nível acurado e a variável conteúdo animal - A houve concordância positiva e baixa $(r=0,37)$. Isto mostra que há uma tendência do grupo de cognição elevada elaborar histórias utilizando palavras precisas, obedecendo uma sequência lógica, incluindo todas as pistas, emoções e relacionamentos retratados na cena (Teglasi, 2001). No que diz respeito às respostas de conteúdo animal, estas supõem uma atividade cognitiva menos complexa, mas de boa definição do estímulo, indicando que o indivíduo responde à tarefa utilizando a energia necessária, resolvendo os problemas de forma simples, prática e aceitável (Exner \& Sendín, 1999).

Quanto a variável detalhe humano, Hd, esta se correlacionou de forma positiva e baixa $(r=0,33)$ com o nível literal de percepção. Esse dado revela que, ao fazer o relato, o indivíduo prende-se ao momento e à descrição da cena e não revela as conexões causais implícitas entre passado, presente e futuro. Geralmente fala sobre pontos da figura, quase como cenas sobrepostas, separadas sem fazer relação uma com a outra (Teglasi, 2001). Com relação aos indicadores Zf, PSV, Sum6, WSum6, GHR, PHR e WDA\%, não se encontraram correlações significativas entre os itens do CAT-A que avaliam nível de percepção. É importante destacar que o método Rorschach, assim como o CAT-A não se destinam especialmente a avaliação do funcionamento perceptivo-cognitivo, embora as respostas pressuponham essas operações. Com exceção do Zf e do WDA\%, as outras variáveis estão mais relacionadas com problemas emocionais e de identidade mais específicos, o que justificaria a ausência de correlações significativas.

\section{Considerações Finais}

Analisando as demandas cognitivas exigidas tanto pelo CAT-A como pelo Método de Rorschach, é possível definir o tipo de processamento intelectual comum às tarefas. Assim, as duas provas exigem fluência verbal, vocabulário, associação entre as partes do estímulo, percepção adequada e interpretação. O CAT-A, segundo os critérios de Teglasi (2001) adaptados para essa pesquisa, avalia como o indivíduo percebe a cena retratada e quão bem ele elabora uma história, exige igualmente uma capacidade de processamento das informações contidas no estímulo/figura com base na percepção e identificação de pessoas, coisas, situações e emoções, relacionando-as em menor ou maior grau.

Com base nos resultados desta pesquisa é possível inferir que os indicadores que avaliam o nível de percepção no CAT-A possibilitam verificar os aspectos relativos ao desenvolvimento intelectual ou cognitivo, uma vez que os mesmos convergem com os dados do DFH Quanto ao método Rorschach, constatou-se que algumas variáveis da tríade cognitiva correlacionaram-se com o CAT-A, indicando como o indivíduo percebe e processa cognitivamente as informações e em seguida adapta essa elaboração às convenções.

Considerando a necessidade de estudos de evidência de validade para o CAT-A e ainda a lacuna existente na literatura científica brasileira de estudos envolvendo o construto cognição, esta pesquisa possibilita afirmar que as categorias de indicadores destacadas para verificar o nível de percepção no CAT-A podem ser consideradas um referencial confiável de análise desse aspecto da personalidade e poderá contribuir para discriminar dificuldades intelectuais daquelas de caráter mais emocional reveladas pela criança que responde ao teste.

Para finalizar, é importante destacar que explorar os aspectos cognitivos por meio do CAT-A não costuma ser o objetivo principal quando se emprega essa técnica, mas verificar sua validade para esse fim contribui tanto para a confiabilidade da técnica quanto para um uso mais abrangente e fidedigno da mesma. Isso abre caminho para novos estudos em busca de evidências de validade para essa técnica projetiva.

\section{Referências}

Adrados, I. (1985). A técnica de Rorschach em crianças. Perfil psicológico da criança dos sete aos quatorze anos. Petrópolis, RJ: Vozes.

Amaral, M. S. C. G., Magarian, T. M., Sousa, A. L. T., \& Aribi, N. V. (2003). A imagem da figura materna e paterna em crianças de 7 a 10 anos por meio das pranchas 3 e 4 do CAT-A. Psykhe, 8(1),19-25.

Antony, S., \& Ribeiro, S. P. (2004). A criança hiperativa: Uma visão da abordagem gestáltica. Psicologia: Teoria e Pesquisa, 20(2), 127-134.

Beizmann, C. (1970). Le Rorschach de l'enfant à l'adulte (3. ed.). Neuchatel, Switzerland: Delachaux et Nestlé.

Bellak, L., \& Bellak, S. S. (1991). Manual do Teste de Apercepção Infantil Figuras de Animais [Children's Apperception Test CAT-A]. Campinas, SP: Livro Pleno. (Original work published 1949)

Benczik, E. B. P. (2005). Crianças com Transtorno de Déficit de Atenção/Hiperatividade: Um Estudo dos Aspectos Psicodinâmicos a Partir do Teste de Apercepção Infantil-CAT-A. (Tese de Doutorado não-publicada). Instituto de Psicologia, Universidade de São Paulo, SP.

Boulanger-Belleyguier, G. (1957). Etude sur le CAT: influence du Stimulus sur lês récits d'enfants de 3 a 8 ans. Revue de Psychologie Appliquée, 7, 1-28.

Castro, L. R. F. (1990). Determinações psicológicas da inibição no trabalho escolar em crianças. (Dissertação de Mestrado não-publicada). Universidade de São Paulo, SP.

Chauhan, N. S., \& Dhar, U. (1981). The psychodynamic side of leprosy (lepra): A Children's Apperception Test (CAT) study. Leprosy in India, 53(3), 379-384.

Colsen, T. L. (2001). Fathers and perinatal Loss: Their conscious and unconscious experiences. Dissertation Abstracts International: Section B. Sciences and Engineering, 62(4-B), 2051. 
Cunha, J. A., Nunes, M. L. T., \& Werlang, B. G. (1991). As respostas ao CAT-A na faixa pré-escolar. Psico (Porto Alegre), 22(2), 89-103.

Dworetzki, G. (1939). Le test de Rorschach et L'Évolution de La Perception. Archives de Psychologie, 27(107-108).

Exner, J. E. (1999). Manual de classificação do Rorschach para o sistema compreensivo. São Paulo, SP: Casa do Psicólogo.

Exner, J. E., \& Sendín, C. (1999). Manual de Interpretação do Rorschach para o sistema compreensivo. São Paulo, SP: Casa do Psicólogo.

Felipe, S. S. R. (1997). A contribuição do Teste de Apercepção Infantil (CAT-A) e do Procedimento de Desenhos de Família com Estórias (DF-E) na avaliação de crianças envolvidas em disputas judiciais. (Dissertação de Mestrado não-publicada). Instituto de Psicologia, Universidade de São Paulo, SP.

Fonseca, A. R. (2005). Abuso sexual na infância: Um estudo de validade de instrumentos. (Dissertação de Mestrado nãopublicada). Universidade São Francisco, Itatiba, SP.

Goodenough, F. L. (1926). Measurement of intelligence by drawings. Yonkers-on-Hudson, NY: World Book.

Grassano, E. (1996). Indicadores psicopatológicos nas técnicas projetivas. São Paulo, SP: Casa do Psicólogo.

Güntert, A. E. V. A., Yazigi, L., \& Behlau, M. S. (2000). Crianças com nódulo vocal: Estudo da personalidade por meio do Método de Rorschach. Psico-USF, 5(1), 43-52.

Harris, D. B. (1963). El test de Goodenough: revision, ampliacion y actualizacion. Buenos Aires, Argentina: Paidós.

Haworth, M. R. (1966). The CAT-Facts about fantasy. New York: Grune and Stratton.

Hirsch, S. B. (1984). El CAT em el psicodiagnostico de niños. Buenos Aires, Argentina: Nueva Visión.

Hirsch, S. B. (1987). Guia de interpretação do Teste de Apercepção Infantil (CAT-A) de L. e S. Bellak. In M. L. S. Ocampo, M. E. G. Arzeno, \& E. G. Piccolo (Eds.), O processo psicodiagnóstico e as técnicas projetivas (pp. 149-166). São Paulo, SP: Martins Fontes.

Hojnoski, R. L., Morrison, R., Brown, M., \& Matthews, W. J. (2006). Projective testuse among school psychologists. Journal of Psychoeducational Assessment, 24(2), 145-159.

Jacquemin, A. (1975). O teste de Rorschach em crianças brasileiras - Pesquisa e Atlas. São Paulo, SP: Vetor.

Lis, A., Mazzeschi, C., Salcuni, S., \& Zennaro, A. (2005). The Children's ApperceptionTest Evaluation Form: Initial data. Psychological Reports, 96(3), 755-768.

Montagna, M. E. (1987). Sistematização da análise do CAT a partir dos esquemas de interpretação de Bellak, Haworth e Shentoub. (Dissertação de Mestrado não-publicada). Pontifícia Universidade Católica de São Paulo, SP.

Paiva, M. L. F. (1992). Relações entre representações cognitivas, afetivas e desempenho escolar em crianças de 4 a 5 anos de idade. (Tese de Doutorado não-publicada). Instituto de Psicologia, Universidade de São Paulo, SP.

Piaget, J. (1978). A formação do símbolo na criança. Rio de Janeiro, RJ: Zahar.

Quartier, V. (2003). Problematique de l'agir et CAT. Psychologie Clinique et Projective, 9, 131-148.

Radoszewska, J. (2006). Sense of self-contact experienced by an obese child. EndokrynolDiabetol Chor Przemiany Materii Wieku Rozw, 12(2),135-139.

Savastano, H. (1977). Estado emocional de alunos da primeira série de um Grupo Escolar - Ginásio da cidade de São Paulo, Brasil. Problemática de saúde pública? Revista de Saúde Pública, 11(4), 480-495.
Scheffler, R. Z. (1975). The child from five to six: A longitudinal study of fantasy change. Genetic Psychology Monographs, 92(1), 19-56.

Sendín, C. (1999). Autopercepção. In J. E. Exner, Manual de Interpretação do Rorschach para o Sistema Compreensivo. São Paulo, SP: Casa do Psicólogo.

Sharan, P., Mehta, M., \& Chaudhry, V. P. (1995). Coping and adaptation in acutelymphoblastic leukemia. Indian Journal of Pediatrics, 62(4), 467-471.

Silva, M. F. X., \& Villemor-Amaral, A. E. (2006). A auto-estima no CAT-A e HTP: Estudo de evidência de validade. Avaliação Psicológica, 5(2), 205-215.

Sisto, F. F. (2005). Desenho da Figura Humana-Escala Sisto. São Paulo, SP: Vetor.

Tardivo, L. S. P. C. (1992). Teste de Apercepção Infantil com Figuras de Animais (CAT-A) e Teste das Fábulas de Düss: Estudos Normativos e Aplicações no Contexto das Técnicas Projetivas. (Tese de Doutorado não-publicada). Universidade de São Paulo, SP.

Tardivo, L. S. P. C., \& Herzberg, E. (1989). Estudo da Percepção no CAT (Children's Apperception Test) numa amostra de crianças de 5 a 8 anos de idade da população da cidade de São Paulo [Resumo]. In Resumenes del VII Congreso de Latinoamericano de Rorschach y otras técnicas proyectivas (p. 49). Buenos Aires, Argentina: Associación Argentina de Psicodiagnóstico de Rorschach.

Teglasi, H. (2001). Essentials of TAT and Other Storytelling Techniques Assessment. New York: John Wiley \& Sons.

Villemor-Amaral, A. E., \& Xavier, M. F. (2007). Avaliação da relação com a figura materna no CAT-A. Psic: Revista de Psicologia da Vetor Editora, 8(2), 195-2003.

Weiner, I. B. (1999). Princípios da Interpretação do Rorschach. São Paulo, SP: Casa do Psicólogo.

Xavier, M. F., \& Villemor-Amaral, A. E. (2010). Precisão entre avaliadores na análise de aspectos cognitivos no CAT-A. In M. L. T. Nunes (Ed.), Técnicas projetivas com crianças (pp. 121-144). São Paulo, SP: Casa do Psicólogo. 
O Conselho Editorial comunica dois erros no Volume 26(1) 2013. No artigo "Escolha do (a) Parceiro (a) Ideal por Heterossexuais:São seus Valores e Traços de Personalidade uma Explicação?", o sobrenome de um dos autores está errado. Onde lia-se Layrtthon Carlos de Oliveira Campos, leia-se Layrtthon Carlos de Oliveira Santos. No artigo "Avaliação do funcionamento cognitivo por meio do CAT-A: evidências de validade", na página $44,3^{\circ}$ parágrafo, $2^{a}$ linha, onde lia-se $(P=0,000)$, leia-se $(p<0,001)$. 